\title{
Relating Hyperspectral Airborne Data to Ground Measurements in a Complex and Discontinuous Canopy
}

\author{
Javier F. CALLEJA ${ }^{1}$, Christine HELLMANN ${ }^{2,3}$, Gorka MENDIGUREN ${ }^{4}$, \\ Suvarna PUNALEKAR ${ }^{5}$, Juanjo PEÓN ${ }^{6}$, Alasdair MacARTHUR ${ }^{7}$, \\ and Luis $\mathrm{ALONSO}^{8}$ \\ ${ }^{1}$ Department of Physics, University of Oviedo, Polytechnic School in Mieres, \\ Mieres, Spain; e-mail: jfcalleja@uniovi.es \\ ${ }^{2}$ University of Bielefeld, Experimental and Systems Ecology, Bielefeld, Germany; \\ e-mail: christine.hellmann@uni-bielefeld.de
}

${ }^{3}$ University of Bayreuth, Agroecosystem Research, BAYCEER, Bayreuth, Germany ${ }^{4}$ Institute of Economy, Geography and Demography, CCHS-CSIC, Madrid, Spain; e-mail: gorka.mendiguren@cchs.csic.es

${ }^{5}$ University of Reading, Department of Geography and Environmental Science, Reading, United Kingdom; e-mail: s.m.punalekar@pgr.reading.ac.uk

${ }^{6}$ Area of Cartographic, Geodesic and Photogrammetric Engineering, University of Oviedo, Polytechnic School in Mieres, Mieres, Spain; e-mail: peonjuan@uniovi.es

${ }^{7}$ NERC Field Spectroscopy Facility, School of Geosciences, University of Edinburgh, Scotland; e-mail: alasdair.macarthur@ed.ac.uk

${ }^{8}$ Image Processing Laboratory, University of Valencia, Paterna, Valencia, Spain; e-mail: luis.alonso@uv.es

\section{Abstract}

The work described in this paper is aimed at validating hyperspectral airborne reflectance data collected during the Regional Experiments For Land-atmosphere EXchanges (REFLEX) campaign. Ground reflectance data measured in a vineyard were compared with airborne reflec- 
tance data. A sampling strategy and subsequent ground data processing had to be devised so as to capture a representative spectral sample of this complex crop. A linear model between airborne and ground data was tried and statistically tested. Results reveal a sound correspondence between ground and airborne reflectance data $(R 2>0.97)$, validating the atmospheric correction of the latter.

Key words: hyperspectral remote sensing, AHS, validation, reflectance field spectrometry.

\section{INTRODUCTION}

Hyperspectral Remote Sensing has been proven to be a very powerful technique in land surface studies (Govender et al. 2009). It has evolved as an important tool for deriving high spectral and spatial resolution information about soil and vegetation (Blackburn 2007, Yao et al. 2010). The applications of hyperspectral data can be cited in various fields like agriculture, forestry and biodiversity, mineral and oil explorations as well as soil characterization. Specifically, narrow band spectral indices derived using this data are particularly efficient in deriving information about land surface, as they rely on the specific spectral response of the targeted object (Cho et al. 2008, Delalieux et al. 2009, haboudane et al. 2004) . These indices have been used mostly in empirical models for retrieval of biophysical parameters like Leaf Area Index (LAI) (Haboudane et al. 2004, Johnson 2003), leaf chlorophyll and dry matter content (Zarco-Tejada et al. 2005 and references therein). They have also been utilized in net photosynthesis models to take into account the plant's physiological status (Dobrowski et al. 2005, Osório et al. 2012). Beyond spectral indices, hyperspectral remote sensing data have also been found useful for complex physically based radiative transfer models (Darvishzadeh et al. 2010, Zarco-Tejada et al. 2004) that are a proxy to the real field spectra. However, irrespective of the approach adapted for exploitation of hyperspectral research it is important to validate this data with appropriately designed scientific field spectroscopic measurements (Anderson et al. 2011). In the case of hyperspectral remote sensing, the trade-off between the spatial and spectral resolution becomes quite critical and so does the field validation plan. Airborne hyperspectral remote sensing applications require high spatial and spectral resolutions. Hyperspectral airborne sensors like the Airborne Hyperspectral Scanner (AHS) offer a full coverage of the visible and near infrared range of the spectrum (400$2500 \mathrm{~nm}$ ) but a spatial resolution limited to a few metres. This spatial resolution may not be high enough for some applications and it determines the validation procedure. Especially for heterogeneous landscapes, capturing the variability through field spectroscopic measurements for the validation of remotely acquired data demands a carefully designed field spectroscopic 
plan. During the Regional Experiments For Land-atmosphere EXchanges (REFLEX) campaign, airborne hyperspectral images were captured by the AHS sensor from Instituto Nacional de Técnicas Aeroespaciales, Spain (INTA) over the Las Tiesas Experimental Farm. This site is a good example of combination of different vegetative covers. It consists of maize field, grassland, bare ground, plantations of various crops and a vineyard (Timmermans et al. 2014). All these land covers are different with respect to their spectral response and hence would need different field spectroscopic plans for proper characterization.

The focus of this paper is on the validation of aerial images over a vineyard. A detailed description of the sampling strategy devised is presented and a thorough statistical analysis is performed, which are the most remarkable contributions of this work. A vineyard field is very heterogeneous due to its row structure, consisting of an irregular canopy mixed with bright and dark soil areas. In this case, scaling-up methods are needed to account for canopy structure and soil reflectance. For these methods to be applied, a characterization of the structure of the vineyard is needed, since structural parameters like separation of rows, relative orientation to the sun and the sensor and height for vines are needed for the models. At the same time, a careful spectroscopic characterization of the vineyard is mandatory. Surface reflectivity spectra measured at ground level are used for validation and model parameterization (Guanter et al. 2007) and in the recalibration of the reflectivity spectra obtained from remote sensing data. Validation of airborne and satellite data over Las Tiesas Experimental Farm has been carried out in previous campaigns. Extensive data can be found concerning validation of satellite-derived products like LAI (Martínez et al. 2009) and thermal airborne data (Sobrino et al. 2006). Regarding reflectance data, comparison of field and airborne reflectance data has also been undertaken in the past. Measurements of reflectance over homogeneous fields of bare soil, barley, and alfalfa were compared with HyMap airborne imaging spectrometer data (Beisl et al. 2000). Reflectance airborne data obtained using the Compact Airborne Spectrographic Imager (CASI) spectrometer and field reflectance data were compared in Guanter et al. (2007) over alfalfa, corn, bare soil, and reforestry fields.

For the spectroscopic characterization, spectroscopic measurements over the vineyard were performed using a GER 1500 spectroradiometer. Taking into consideration the pixel size of airborne images in this work $(3 \mathrm{~m})$, it can be stated that the pixels in the image would always be mixture of spectral signatures of soil and vegetation. Hence, a sampling strategy had to be devised so that the area sampled was representative of the heterogeneity of the field. 


\section{EXPERIMENTAL PROCEDURE}

\subsection{Description of the test sites}

Field measurements were conducted in a vineyard at Las Tiesas Experimental Farm $\left(39^{\circ} 3.544^{\prime} \mathrm{N}, 2^{\circ} 6.082^{\prime} \mathrm{W}\right.$, elevation $c a .700 \mathrm{~m}$ a.s.1., Fig. 1), located in the La Mancha region in Southern Spain, ca. $20 \mathrm{~km}$ west of Albacete. Flat morphology and large, uniform land use units render Las Tiesas a suitable test site for remote sensing applications. Approximately $65 \%$ of the area is dry land and $35 \%$ is irrigated and cultivated with different crops. The climate is Mediterranean, with low average annual rainfall $(400 \mathrm{~mm})$, which is mainly concentrated in spring and autumn. La Mancha is among the driest regions of Europe, with water tables between 20 and $30 \mathrm{~m}$ below the land surface.

The vineyard covers an area of $c a .6 .8$ ha and it is irrigated. Field measurements were restricted to an area of 2.4 ha in the northern part of the vineyard (Fig. 1b), which was planted with the same variety of vine (Vitis vini-

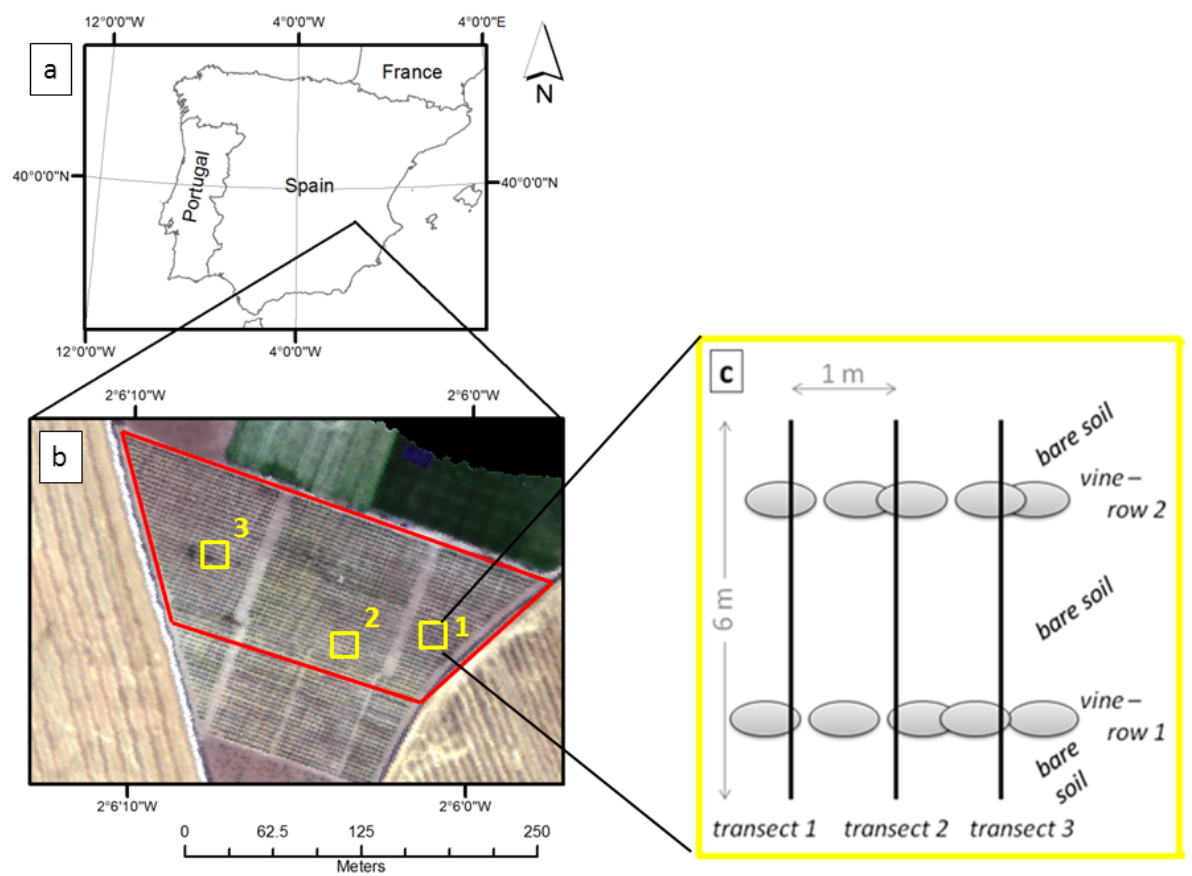

Fig. 1: (a) Location of the study site within Spain; (b) Aerial image of the vineyard. Real colour composite with AHS channel centred at $650 \mathrm{~nm}$ as red, AHS channel centred at $530 \mathrm{~nm}$ as green and AHS channel centred at $471 \mathrm{~nm}$ as blue. The study site is framed in a red box. Approximate locations of plots 1-3, where field measurements were conducted, are demarcated by yellow boxes; (c) Schematic depicting of the sampling strategy within each plot (please see text for details). 
fera). Vines were $c a .1 .3 \mathrm{~m}$ in height and were planted in roughly NW-SE oriented rows approximately $3 \mathrm{~m}$ apart, with a cross-row canopy extension of approximately $0.2-0.3 \mathrm{~m}$ at the time of the study. Areas in between the rows were dominated by bare soil with some sparse cover of small forbs.

\subsection{Field measurements and airborne data}

Within the vineyard, three plots $\left(3 \times 6 \mathrm{~m}^{2}\right)$ were randomly chosen (Fig. 1b), each consisting of 3 transects. Transects were $1 \mathrm{~m}$ apart and $6 \mathrm{~m}$ long, such that the starting and end points of each transect would be in the middle in between two rows of vines, and the transects would cross two rows of vines (Fig. 1c). One $6 \mathrm{~m}$ transect can thus be considered the smallest "homogenous" measurement unit, such that although the transects were moved within the vineyard, it would always cover two rows of vines and two inter-row areas (from now on referred to as bare soil), i.e., fractions of canopy and bare soil would be representative for any given $6 \mathrm{~m}$ transect within the study site. Plot 1 and the first transect of plot 2 were sampled on 25 July 2012, from 8:00 to 10:10 UTC; transect 2 and 3 of plot 2 and complete plot 3 were sampled on 26 July 2012, 8:20 to 11:59 UTC. Airborne data were acquired on the same dates as the field measurements, and nearly simultaneously. On 25 July 2012 airborne data acquisition started at 8:41 UTC and was completed at 9:47 UTC. On 26 July 2012 airborne data acquisition started at 8:42 UTC and was completed at 9:38 UTC (de Miguel et al. 2015, Timmermans et al. 2014).

Two GER 1500 spectroradiometers (Spectra Vista Corporation, Poughkeepsie, NY, USA) were operated in Dual-Beam Bi-Conical mode, using a notebook equipped with the DFOV 1500 software. In the Dual-Beam BiConical mode, one spectroradiometer (from now on target sensor) can be used to measure the target, while the second device (from now on reference sensor) simultaneously measures the Spectralon reference panel. This mode of operation provides simultaneous measurements of reference and target, minimizing uncertainties due to changes in irradiance between target and reference scans. To complete the measurement procedure, a reference panel must be measured using the target sensor to allow for intercalibration of both spectrometers. These measurements were performed at the beginning and at the end of each plot. Two different Spectralon reference panels were used, one for each spectrometer. The spectral response of both Spectralon reference panels $\left(25 \times 25 \mathrm{~cm}^{2}\right.$ reflective area, Labsphere Inc., North Sutton, NH, USA) was known. For target measurements, the reference sensor remained at a fixed point over the reference panel, with both, sensor and reference panel, being fixed to tripods. The target sensor was mounted to the top of a $2.8 \mathrm{~m}$ pole, using a tripod and duct tape. The angle between pole and spec- 
trometer was set to $c a .25^{\circ}$, so that when the pole was tilted by $c a .25^{\circ}$, measurements could be taken from $2.5 \mathrm{~m}$ height from nadir, with the operator interfering as little as possible with the field of view of the sensor. GER 1500 spectroradiometers recorded the spectral range from 350 to $1050 \mathrm{~nm}$, with a spectral resolution of $3.2 \mathrm{~nm}$ and a sampling interval of $1.5 \mathrm{~nm}$. $8^{\circ}$ foreoptics were used, resulting in a field of view of $35 \mathrm{~cm}$ on the ground with a measuring height of $2.5 \mathrm{~m}$. With this field of view, and given the cross-row canopy extension and the separation of the rows of vines, the field spectrum of soil contains most probably pure soil information, whilst the field spectrum of the vegetation contains for sure not only vegetation but soil information too. Integration speed was set to automatic. Each sample represents the average of 16 scans. GER 1500 devices were switched on and warmed up at least $20 \mathrm{~min}$ before the start of measurements. Intercalibration was conducted between reference and target sensor and finally Hemispherical Conical Reflectance Factor (HCRF) (Schaepman-Strub et al. 2006) was calculated following the methodology proposed by NERC Field Spectroscopy Facility (Anderson et al. 2011). Once this step was done, all spectra were resampled to match the spectral resolution of the AHS sensor using the spectral response function of each band provided by INTA. In order to capture a representative sample, i.e., an unbiased representation of fractional covers of vegetation and bare soil within one transect, spectra were recorded every $25 \mathrm{~cm}$ on each transect. Transects and the measuring points were marked on the ground, so the operator just needed to place the pole at each point ensuring consistency in the measurements along time. Taking into account the field of view of $35 \mathrm{~cm}$, transects were thus completely recorded by this method. In total, 236 spectra were collected. Differences in illumination conditions during field measurement acquisition were considered. Due to the orientation of the vines (NW-SE) and the time at which the field measurements were taken (7:30 to 10:00 UTC) the shadow effect in soil measurements was minimum as sun azimuth at 7:30 UTC is $85^{\circ}$ whilst at 10:00 UTC is $114^{\circ}\left(0^{\circ}\right.$ taken pointing north). Furthermore, as nadir looking geometry was maintained for the measurements, we assume that the target measurements on top of the canopy were captured with least fraction of shadow possible. As we will see below, the role of shadows is also minimized by discarding the four adjacent measurements on both sides of the vines, avoiding thus the areas most affected by shadows.

Airborne hyperspectral data were acquired using AHS sensor mounted on a CASA 212-200 aircraft, property of INTA. Several flights were undertaken simultaneously to ground measurements. The data presented in this paper correspond to the flight at 8:43 a.m. on 25 July 2012 at an altitude of $1700 \mathrm{~m}$ a.s.l. Figure 2 is a false colour composite of the area covered by the flight. The INTA AHS sensor has 63 channels in the reflective part of the 


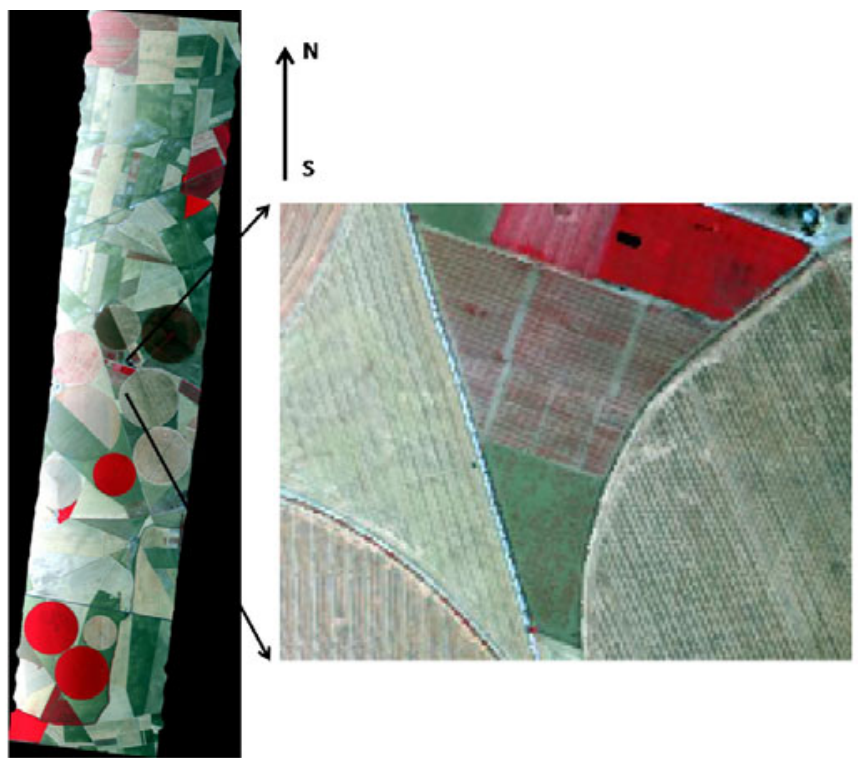

Fig. 2. False color RGB composite of the flight line (left) and of an enlarged image of the vineyard (right), taking the AHS channel centred at $856 \mathrm{~nm}$ as red, the channel centred at $650 \mathrm{~nm}$ as green, and the channel centred at $530 \mathrm{~nm}$ as blue.

electromagnetic spectrum ( 20 bands from 442 to $1019 \mathrm{~nm}, 1$ band from 1491 to $1650 \mathrm{~nm}$, and 20 bands from 2028 to $2498 \mathrm{~nm}$ ), 7 bands in the 3 to $5 \mathrm{mi}-$ crons range, and 10 bands in the 8 to 13 microns range. The Instantaneous Field Of View (IFOV) is $2.5 \mathrm{mrad}$ with a Field Of View (FOV) of $90^{\circ}$. The Full Width Half Maximum (FWHM) of the bands from 442 to $1019 \mathrm{~nm}$ (the bands that coincide with the GER spectral range) is $27-30 \mathrm{~nm}$. At sensor radiance data were corrected by INTA using ATmospheric CORrection (ATCOR4) (Richter and Schläpfer 2011) to produce Hemispherical Directional Reflectance Factor (HDRF) since ATCOR4 does not correct for the hemispherical irradiance (Schaepman-Strub et al. 2006). In this way we assure that ground and airborne reflectance products are comparable. Data were subsequently georeferenced to a 3-m-on-a-side pixel.

After resampling of the ground measurements, each spectral HDRF and HCRF consists of 19 values of reflectance, each one for each of the 19 AHS channels from 442 up to $973 \mathrm{~nm}$.

\subsection{Modeling}

Once the data from both sources was comparable, a statistical approach was applied to understand some of the issues on the upscaling process in a heterogeneous crop such as a vineyard. It is well known that the agreement be- 
tween airborne and ground spectra depends on the nature of the target, spatial resolution, viewing geometry, and regarding remote sensing of vegetation; it becomes less when the proportion of soil increases (Guanter et al. 2007). In the case of the vineyard field, given the pixel size and the distribution of soil and vines, airborne spectra were modelled as a linear combination of two ground reflectances, representing domination of soil and vegetation, respectively:

$$
\text { (AHS) }=S \times \rho_{s}+V \times \rho_{v}, \quad S, V \geq 0 .
$$

where $\rho$ (AHS) is the HDRF obtained from airborne data (the reflectance spectrum of a pixel), and $\rho_{s}$ and $\rho_{v}$ are soil and vegetation ground HCRF spectra obtained using the GER spectroradiometer. Spectral signatures $\rho_{s}$ and $\rho_{v}$ do not have to be understood as pure-soil and pure-vegetation ground spectral signatures, but as two spectral signatures obtained from ground measurements that represent the two ends of all the measured mixed soilvegetation spectra. This is clearly understood in the case of $\rho_{v}$, since even in the case of measuring just above the canopy, some signal from the soil will enter the radiometer, due to the FOV of the instrument, the sparse canopy and the reflected soil energy transmitted from the canopy. Coefficients $S$ and $V$ are the contributions of each of these ground endspectra to the spectrum of each pixel. Since we are comparing ground against airborne data the restriction $S+V \leq 1$ was not imposed. This analysis is not intended to be a spectral unmixing to obtain abundances of soil and vegetation. Further analysis should be carried out in order to obtain the spectral unmixing endmembers from $\rho_{s}$ and $\rho_{v}$ like matching field spectra with the image endmembers spectra (Schmid et al. 2004) or other techniques (Quintano et al. 2012). The restriction $S+V=1$ must have been imposed in the case of having obtained $\rho_{s}$ and $\rho_{v}$ as image endmembers or after having related them to the image endmembers. Nevertheless, $S$ and $V$ provide an estimation of the weight of soil and vegetation in the pixel spectrum. As we will see later, for some pure soil pixels we obtained $V=0$ and $S>1$, an unsurprising result since $\rho_{s}$ is not the soil endmember of the image.

\section{RESULTS AND DISCUSSION}

For each plot, we obtained $\rho_{s}$ and $\rho_{v}$ as the mean values of the reflectance spectra of soil targets and vegetation targets, respectively, as explained below. To identify a target as soil target or vegetation target we used the ground NDVI obtained from the GER field spectra, named NDVI_GER. Figure 3 shows the NDVI_GER for all the targets measured in the three plots. In order to calculate $\rho_{v}$ for each plot, we firstly identified the six targets with maximum NDVI_GER. We then calculated the reflectance spec- 


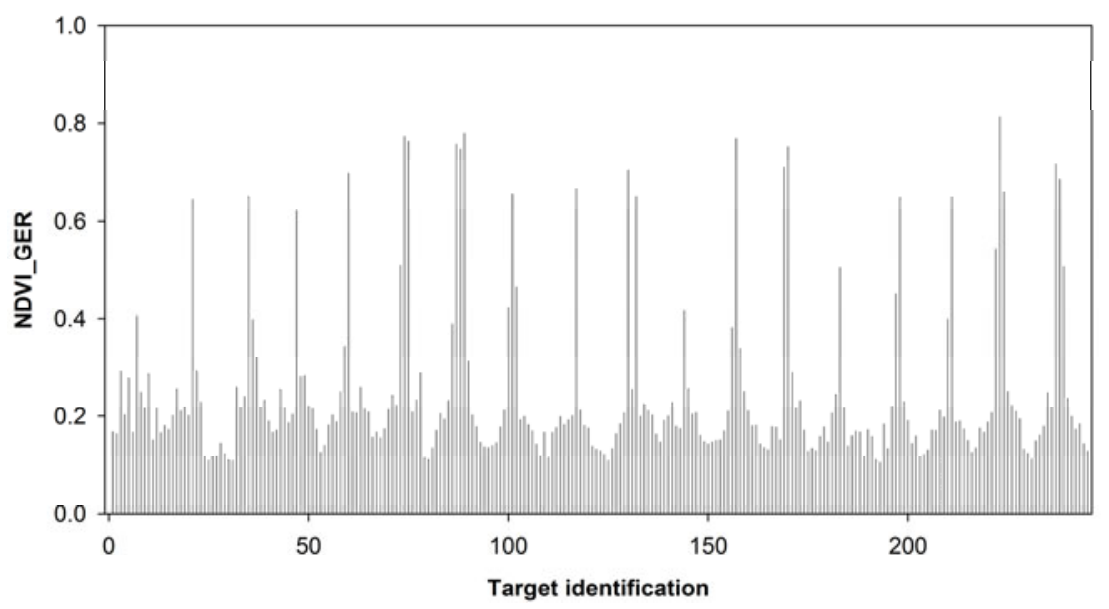

Fig. 3. NDVI obtained from field reflectance spectra taken on transects across the vine rows (NDVI_GER). Target measurements were given consecutive numbers. The periodicity in NDVI_GER reflects the transitions between soil- and vegetationdominated targets as moving across the rows of vine.

trum of vegetation for each plot as the mean value of the six targets with maximum NDVI_GER. We took 6 targets since, according to the sampling strategy described above, the spectroradiometer was placed just above the vine canopy 6 times exactly on each plot. So those targets with the maximum NDVI_GER correspond to measurements taken just above the vine canopy. Ground soil reflectance spectrum $\rho_{s}$ was then calculated as the mean of the rest of the targets, ignoring the four nearest targets to those with the maximum NDVI_GER (corresponding to two targets at each side of the vine) in order to avoid contamination from the canopy.

Figures 4 and 5 show the correlation between $\rho_{v}$ and $\rho_{s}$ for the three plots (named $\mathrm{P}_{1}, \mathrm{P}_{2}$, and $\mathrm{P}_{3}$ ) measured in the vineyard for the 19 bands between 442 and $973 \mathrm{~nm}$. It is noteworthy that $\rho_{v}$ and $\rho_{s}$ for the three plots exhibit a linear relationship between each other with very high correlation, a slope close to 1 and a very small offset (see the fitting equations inserted in Figs. 4 and 5).

Thus, $\rho_{v}$ and $\rho_{s}$ from one single plot are representative for all three plots, suggesting that $\rho_{v}$ and $\rho_{s}$ from one single plot can be used to describe the part of the vineyard framed in the red box in Fig. 1; let us remind that the southern part of the vineyard is not taken into account since it has a slightly different structure.

The spectral properties of the soil and the vegetation change from sample to sample. But since the variety of vine is the same over the whole area under study and the soil is homogeneous, it has to be possible to find a repre- 


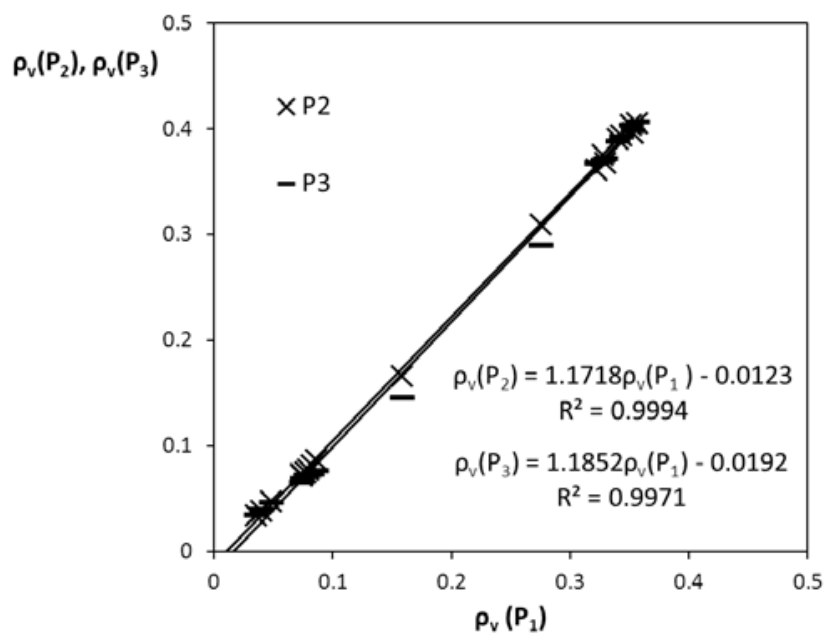

Fig. 4. Correlation between ground $\rho_{v}$ measured in the three plots, $\mathrm{P}_{1}, \mathrm{P}_{2}$, and $\mathrm{P}_{3}$. Least-square fits of $\rho_{v}\left(\mathrm{P}_{2}\right)$ versus $\rho_{v}\left(\mathrm{P}_{1}\right)$ and $\rho_{v}\left(\mathrm{P}_{3}\right)$ versus $\rho_{v}\left(\mathrm{P}_{1}\right)$ are presented.

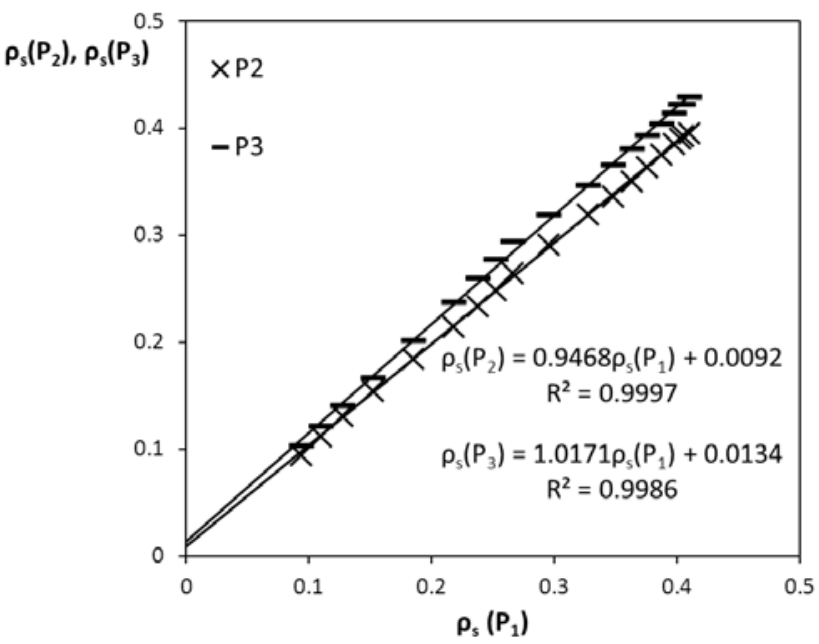

Fig. 5. Correlation between ground $\rho_{s}$ measured in the three plots, $\mathrm{P}_{1}, \mathrm{P}_{2}$, and $\mathrm{P}_{3}$. Least-square fits of $\rho_{s}\left(\mathrm{P}_{2}\right)$ versus $\rho_{s}\left(\mathrm{P}_{1}\right)$ and $\rho_{s}\left(\mathrm{P}_{3}\right)$ versus $\rho_{s}\left(\mathrm{P}_{1}\right)$ are presented.

sentative spectrum of the soil and of the vegetation of the study area. A good sampling strategy has to be able to provide these representative spectra. The results shown in Figs. 4 and 5 prove that the sampling strategy was correct; otherwise, different $\rho_{v}$ and $\rho_{s}$ would have been obtained for each plot.

To investigate the validity of the linear relationship between airborne and ground data (Eq. 1), $\rho_{v}$ and $\rho_{s}$ from plot 1 are going to be used from now on. Each pixel in the image is supposed to have $\rho_{v}$ and $\rho_{s}$ of plot 1 , and then the 


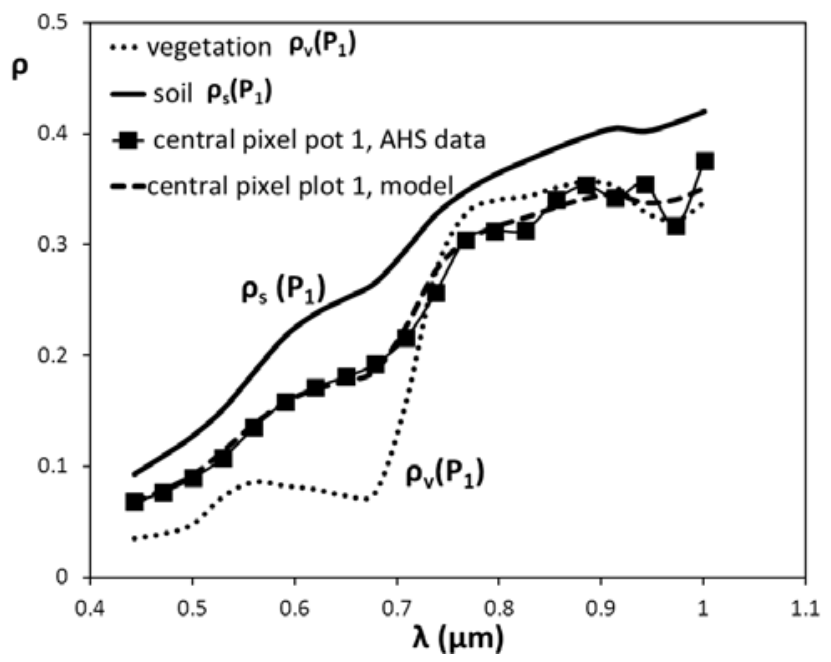

Fig. 6. AHS reflectance spectral signature for a pixel located at plot 1 and the fit to the ground spectra using the model in Eq. 1.

actual reflectance spectrum of that pixel is used to calculate $S$ and $V$ using Eq. 1. The hypothesis of a linear relationship between $\rho$ (AHS) and $\rho_{v}$ and $\rho_{s}$ will be tested using the determination coefficient $R^{2}$ of the fit and the $p$ values of the $t$-test on coefficients $S$ and $V$ for each pixel. As an example, ground $\rho_{v}$ and $\rho_{s}$ as a function of wavelength from plot 1 are plotted in Fig. 6, along with the reflectance for a pixel located at plot 1, $\rho$ (AHS), and the reflectance fitted using Eq. 1 .

The model was applied for the whole vineyard. For each pixel, we calculated the values of $S, V$, and the corresponding $p$-values along with the determination coefficient $R^{2}$ of the fit. Results are shown in Figs. 7-10. The model can be considered of statistical significance (with a significance level of 5\%) for those pixels for which $p$-value $(S)<0.05$ and $p$-value $(V)<0.05$. Results are shown in Table 1 . According to these results, 230 pixels $(8.3 \%)$ can be regarded as pure soil $(V=0)$, corresponding to the two parallel wide

Table 1

Distribution of pixels according to the values of $V, S$, and their $p$-values

\begin{tabular}{|c|c|c|}
\hline$S, V, p$-value $(S), p$-value $(V)$ & Number of pixels & Percentage \\
\hline$V>0$ and $p$-value $(V)<0.05$ & 2351 & 84.8 \\
$V>0$ and $p$-value $(V)>0.05$ & 190 & 6.9 \\
$V=0$ & 230 & 8.3 \\
$S>0$ and $p$-value $(S)<0.05$ & 2771 & 100 \\
\hline
\end{tabular}




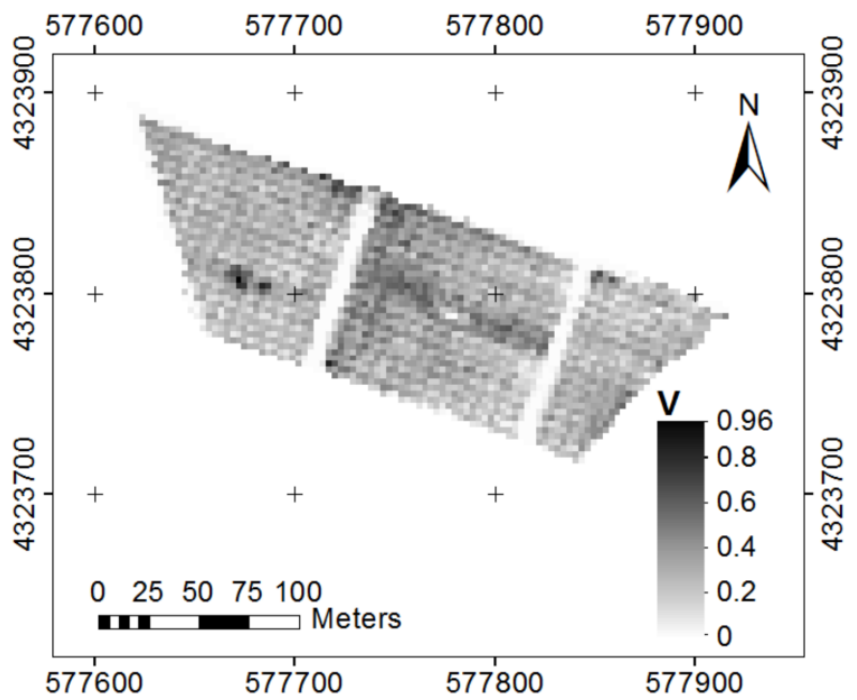

Fig. 7. Distribution of the values of $V$ across the vineyard. Pixels with $V=0$ represent pure soil pixels. Map is provided in UTM WGS-84 30N.

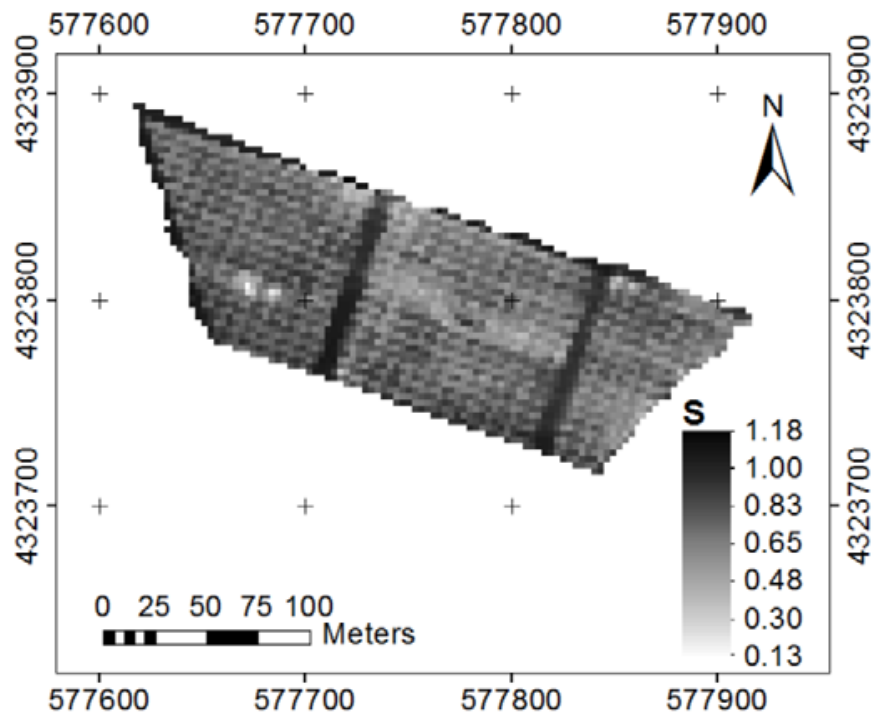

Fig. 8. Distribution of the values of $S$ across the vineyard. Map is provided in UTM WGS-84 30N.

soil paths crossing the vineyard from NE to SW. Moreover, the model provides values of $V$ with $p$-value $(V)>0.05$ for only $6.9 \%$ of the pixels. $S>0$ with a $p$-value below 0.05 were obtained in $100 \%$ of the pixels. 


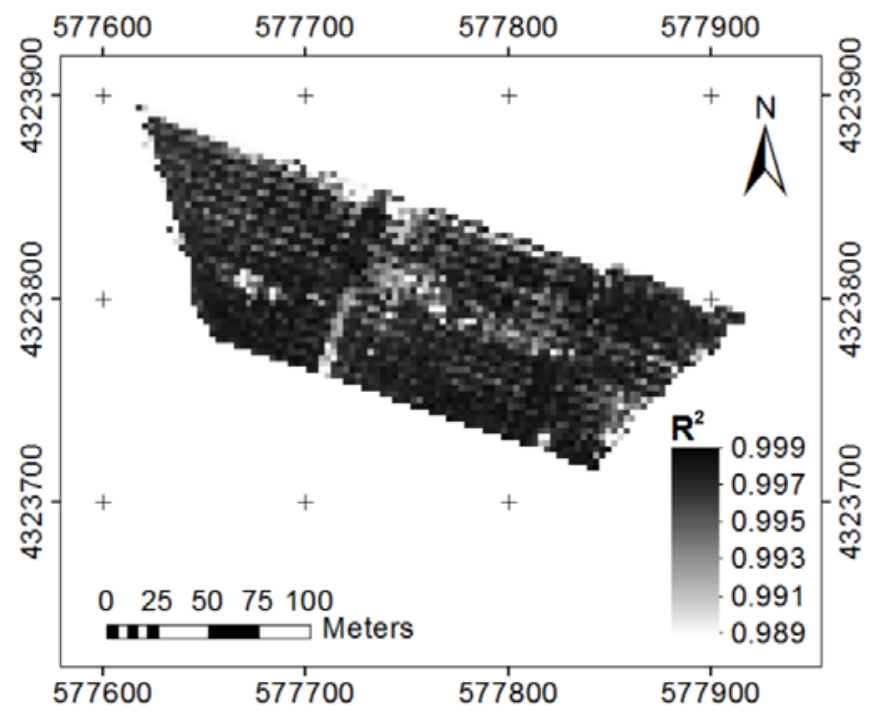

Fig. 9. Distribution of the values of $R^{2}$ across the vineyard. Map is provided in UTM WGS-84 30N.

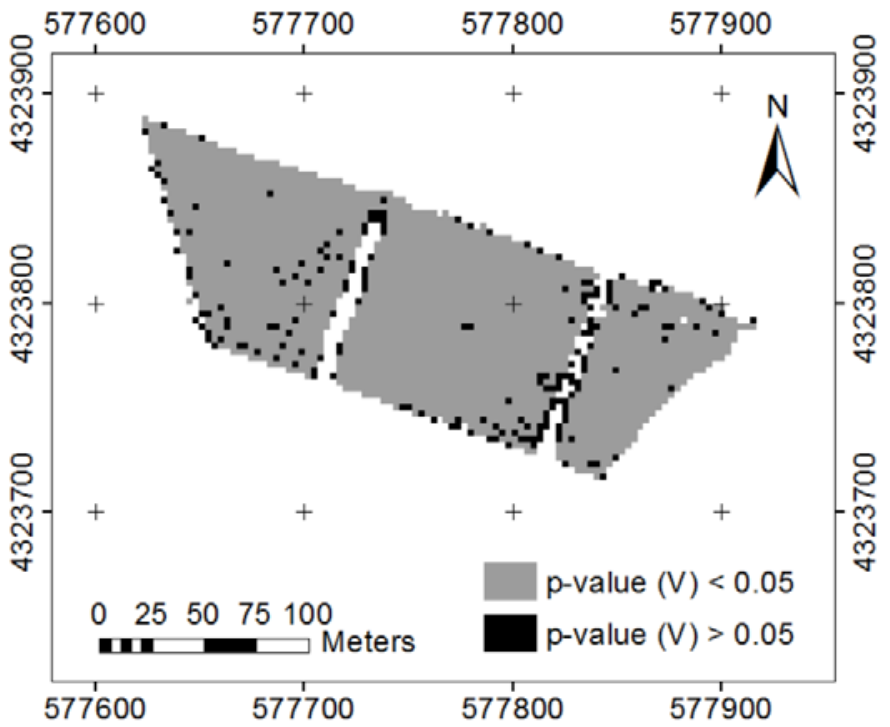

Fig. 10. Distribution of the values of $p$-value $(V)$ across the vineyard. White pixels have $V=0$ (pure soil pixels). Map is provided in UTM WGS-84 30N.

The obtained values of $V$ and $S$ clearly reproduce the rowed structure of the vineyard, as can be seen in Figs. 7 and 8. Rows of alternatively high (low) and low (high) $S(V)$ values running parallel to the vines were obtained. 
The high values of $R^{2}$ obtained across the vineyard confirm the validity of the model. It is noteworthy that pixels with $p$-value $(V)>0.05$ are mainly located in the vicinity of soil paths (see Fig. 10) where no reliable, extremely low $V$ values are expected. On the other hand, shadows might affect the vegetation field spectra more, and this is shown in the larger number of pixels with $p$-value $(V)>0.05(6.9 \%$ of the pixels $)$ than pixels with $p$-value $(S)>$ 0.05 ( $0 \%$ of the pixels).

The results from the statistical analysis confirm that the sampling strategy is suited to capture the variability of the site. They can also be used as a validation of airborne data and of the atmospheric correction performed. Previous studies of reflectance performed over the same site do not provide a description of the sampling strategy and lack a sound statistical analysis of the data. In the case of the HyMap airborne imaging spectrometer data (Beisl et al. 2000) over bare soil, barley and alfalfa, the disagreement between field and airborne data was attributed to either the varying angular behaviour of the reflectance or to the fact that non-representative samples were collected in the field. In the case of the CASI spectrometer over bare soil, alfalfa, corn and reforestry (Guanter et al. 2007), the agreement between airborne and field reflectance data became worse when the proportion of soil increased, explained by those authors as probably due to the high heterogeneity of bare soils. A thorough statistical analysis of the results was not given in any of the two studies.

In order to reinforce the results, we tried to correlate coefficient $V$ with vegetation properties. Coefficient $V$ is expected to provide information about the condition of the canopy. To confirm this, we plotted the value of the NDVI measured from AHS data (NDVI_AHS) versus the value of $V$ for

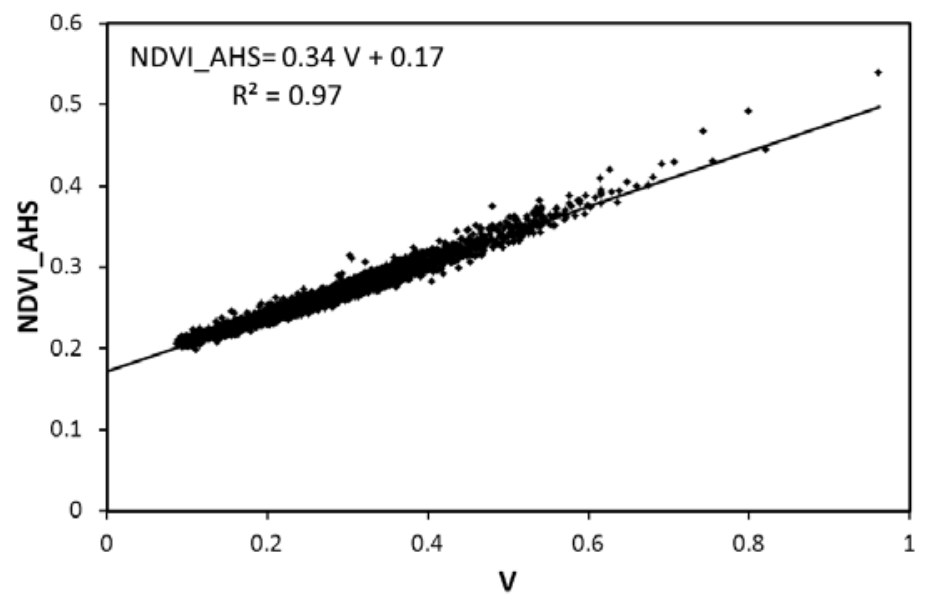

Fig. 11. NDVI_AHS versus $V$ for 2351 pixels with $V>0$ and $p$-value $(V)<0.05$. 
the 2351 vineyard pixels for which $V>0$ and $p$-value $(V)<0.05$ (Fig. 11). A strong correlation was confirmed. The offset $(0.17)$ would provide an estimation of the mean value of the NDVI of the soil.

\section{CONCLUSIONS}

Validation of airborne hyperspectral HDRF product has been carried out comparing airborne data with ground measurements over a vineyard. A sampling strategy was devised and a subsequent ground data processing was undertaken in order to obtain ground reflectance products comparable to airborne ones. Ground spectral reflectance of a pixel area was simulated as a linear combination of soil and vegetation contributions and then compared to airborne spectral reflectance on a pixel by pixel basis. Statistical analyses show that there is a strong correlation between airborne and ground data. These results indicate that a sound atmospheric correction has been performed for the AHS bands under consideration.

Acknowledgments. The research leading to these results has received funding from the European Community's 7th Framework Programme (FP7/2008-2013) under EUFAR contract No. 227159, Cost Action ES0903EUROSPEC and ESA Grant D/EOP/rp/2012/48".

\section{References}

Anderson, K., J.L. Dungan, and A. MacArthur (2011), On the reproducibility of field-measured reflectance factors in the context of vegetation studies, Remote Sens. Environ. 115, 8, 1893-1905, DOI: 10.1016/j.rse.2011.03.012.

Beisl, U., G. Strub, and C. Dickerhof (2000), Validation of hyperspectral imaging data from the Barrax test site with BRDF ground measurements in the reflective wavelength range. In: 2nd EARSeL Workshop on Imaging Spectroscopy, 11-13 July 2000, Enschede, The Netherlands.

Blackburn, G.A. (2007), Hyperspectral remote sensing of plant pigments, J. Exp. Bot. 58, 4, 855-867, DOI: $10.1093 / \mathrm{jxb} / \mathrm{erl} 123$.

Cho, M.A., I. Sobhan, A.K. Skidmore, and J. de Leeuw (2008), Discriminating species using hyperspectral indices at leaf and canopy scales, Int. Arch. Photogram. Remote Sens. Spat. Inf. Sci. 37, B7, 369-376.

Darvishzadeh, R., C. Atzberger, A. Skidmore, and M. Schlerf (2010), Retrieval of vegetation biochemicals using a radiative transfer model and hyperspectral data. In: W. Wagner, and B. Székely (eds.), TC VII Symposium - 100 Years ISPRS - Advancing Remote Sensing Science, 5-7 July 2010, Vienna, Austria, 171-175. 
de Miguel, E., M. Jiménez, I. Pérez, O.G. de la Cámara, F. Muñoz, and J.A. GómezSánchez (2015), AHS and CASI processing for the REFLEX remote sensing campaign: methods and results, Acta Geophys. 63, 6, 1485-1498, DOI: 10.1515/acgeo-2015-0031 (this issue).

Delalieux, S., B. Somers, W.W. Verstraeten, J.A.N. van Aardt, W. Keulemans, and P. Coppin (2009), Hyperspectral indices to diagnose leaf biotic stress of apple plants, considering leaf phenology, Int. J. Remote Sens. 30, 8, 18871912, DOI: 10.1080/01431160802541556.

Dobrowski, S.Z., J.C. Pushnik, P.J. Zarco-Tejada, and S.L. Ustin (2005), Simple reflectance indices track heat and water stress-induced changes in steady-state chlorophyll fluorescence at the canopy scale, Remote Sens. Environ. 97, 3, 403-414, DOI: 10.1016/j.rse.2005.05.006.

Govender, M., P.J. Dye, I.M. Weiersbye, E.T.F. Witkowski, and F. Ahmed (2009), Review of commonly used remote sensing and ground-based technologies to measure plant water stress, Water $S A 35,5,741-752$, DOI: 10.4314 /wsa. v35i5.49201.

Guanter, L., V. Estellés, and J. Moreno (2007), Spectral calibration and atmospheric correction of ultra-fine spectral and spatial resolution remote sensing data. Application to CASI-1500 data, Remote Sens. Environ. 109, 1, 54-65, DOI: 10.1016/j.rse.2006.12.005.

Haboudane, D., J.R. Miller, E. Pattey, P.J. Zarco-Tejada, and I.B. Strachan (2004), Hyperspectral vegetation indices and novel algorithms for predicting green LAI of crop canopies: Modeling and validation in the context of precision agriculture, Remote Sens. Environ. 90, 3, 337-352, DOI: 10.1016/j.rse. 2003.12.013.

Johnson, L.F. (2003), Temporal stability of an NDVI-LAI relationship in a Napa Valley vineyard, Aust. J. Grape Wine Res. 9, 2, 96-101, DOI: 10.1111/j. 1755-0238.2003.tb00258.x.

Martínez, B., F.J. García-Haro, and F. Camacho-de Coca (2009), Derivation of highresolution leaf area index maps in support of validation activities: Application to the cropland Barrax site, Agr. Forest Meteorol. 149, 1, 130-145, DOI: $10.1016 /$ j.agrformet.2008.07.014.

Osório, J., M.L. Osório, and A. Romano (2012), Reflectance indices as nondestructive indicators of the physiological status of Ceratonia siliqua seedlings under varying moisture and temperature regimes, Funct. Plant Biol. 39, 7, 588-597, DOI: 10.1071/FP11284.

Quintano, C., A. Fernández-Manso, Y.E. Shimabukuro, and G. Pereira (2012), Spectral unmixing, Int. J. Remote Sens. 33, 17, 5307-5340, DOI: 10.1080/ 01431161.2012.661095.

Richter, R., and D. Schläpfer (2011). Atmospheric/topographic correction for airborne imagery. DLR Report, DLR-IB 565-02/11, Wessling, Germany.

Schaepman-Strub, G., M.E. Schaepman, T.H. Painter, S. Dangel, and J.V. Martonchik (2006), Reflectance quantities in optical remote sensing-definitions 
and case studies, Remote Sens. Environ. 103, 1, 27-42, DOI: 10.1016/ j.rse.2006.03.002.

Schmid, T., M. Koch, J. Gumuzzio, and P.M. Mather (2004), A spectral library for a semi-arid wetland and its application to studies of wetland degradation using hyperspectral and multispectral data, Int. J. Remote Sens. 25, 13, 24852496, DOI: 10.1080/0143116031000117001.

Sobrino, J.A., J.C. Jiménez-Muñoz, P.J. Zarco-Tejada, G. Sepulcre-Cantó, and E. de Miguel (2006), Land surface temperature derived from airborne hyperspectral scanner thermal infrared data, Remote Sens. Environ. 102, 1-2, 99-115, DOI: 10.1016/j.rse.2006.02.001.

Timmermans, W., C. van der Tol, J. Timmermans, M. Ucer, X. Chen, L. Alonso, J. Moreno, A. Carrara, R. Lopez, F. de la Cruz Tercero, H.L. Corcoles, E. de Miguel, J.A.G. Sanchez, I. Pérez, B. Franch, J.-C.J. Munoz, D. Skokovic, J. Sobrino, G. Soria, A. MacArthur, L. Vescovo, I. Reusen, A. Andreu, A. Burkart, C. Cilia, S. Contreras, C. Corbari, J.F. Calleja, R. Guzinski, C. Hellmann, I. Herrmann, G. Kerr, A.-L. Lazar, B. Leutner, G. Mendiguren, S. Nasilowska, H. Nieto, J. Pachego-Labrador, S. Pulanekar, R. Raj, A. Schikling, B. Siegmann, S. von Bueren, and Z. Su (2015), An overview of the Regional Experiments for Land-atmosphere Exchanges 2012 (REFLEX 2012) Campaign, Acta Geophys. 63, 6, 1465-1484, DOI: 10.2478/s11600-014-0254-1 (this issue).

Yao, Y., N. Wei, Y. Chen, Y. He, and P. Tang (2010), Soil moisture monitoring using hyper-spectral remote sensing technology. In: Q. Luo (ed.), 2010 2nd IITA Int. Conf. on Geoscience and Remote Sensing (IITA-GRS), 28-31 August 2010, Qingdao, China, IEEE, 373-376, DOI: 10.1109/IITA-GRS.2010. 5604219.

Zarco-Tejada, P.J., J.R. Miller, J. Harron, B. Hu, T.L. Noland, N. Goel, G.H. Mohammed, and P. Sampson (2004), Needle chlorophyll content estimation through model inversion using hyperspectral data from boreal conifer forest canopies, Remote Sens. Environ. 89, 2, 189-199, DOI: 10.1016/j.rse.2002. 06.002 .

Zarco-Tejada, P.J., A. Berjón, R. López-Lozano, J.R. Miller, P. Martín, V. Cachorro, M.R. González, and A. de Frutos (2005), Assessing vineyard condition with hyperspectral indices: Leaf and canopy reflectance simulation in a row-structured discontinuous canopy, Remote Sens. Environ. 99, 3, 271287, DOI: $10.1016 /$ j.rse.2005.09.002.

Received 30 January 2014

Received in revised form 15 December 2014

Accepted 5 January 2015 